\title{
Hourly simulations of an hospital building for assessing the thermal demand and the best retrofit strategies for consumption reduction.
}

\author{
Federico Silenzi*, Antonella Priarone, Marco Fossa \\ DIME - Dept. of Mechanical Energy, Management and Transportation Engineering, \\ University of Genoa, Italy, Via Opera Pia 15a, 116145 Genova, Italy \\ *e-mail: federico.silenzi@edu.unige.it
}

\begin{abstract}
In the framework of energy saving and environmental protection, the role of the energy consumption in buildings is crucial. For existing buildings and especially for public ones, it is mandatory to correctly select and realize suitable retrofitting interventions to reduce costs and increase the efficiency. In fact, innovative solutions for both the envelope and the plants renovation are often very expensive and the correct choice becomes critical for the sustainability from the economic point of view.

The aim of the present paper is to propose a methodology to optimize the process of selection for the retrofit interventions, here applied to a case study of the Monoblocco Pavilion at the San Martino Hospital in Genova, Italy. The building thermal behaviour is dynamically simulated by means of a Energy Plus model in order to evaluate the energy needs for both heating and cooling purposes. The base case scenario is evaluated in terms of key performance indicators (KPIs) and compared with benchmark values in order to select the more suitable intervention actions. For the analyzed case study, the innovative retrofit solutions are façade void insulated panels, smart rotating windows with different emissivity glass and sunlight carrying optical-fibres coupled with dimmed LED lighting system. The technologies are combined in different intervention packages that are then compared in term of energy saving and economic sustainability by means of the estimation of hourly values of energy consumption and the assessment of the Simply Pay Back Period (SPB) of the investment.
\end{abstract}

KEYWORDS: Energy Saving, Buildings, Retrofitting, Energy Plus, Dynamic Simulations.

\section{INTRODUCTION}

Nowadays energy consumption in buildings is very high, reaching in Europe the value of $39 \%$ of the total energy consumption for commercial and residential buildings [1].

In this framework is very relevant the role of non-residential buildings (NR-buildings) for which the energy

consumption due to space heating is coupled with a very high electrical energy consumption, constantly increasing, due to the extensive use of HVAC for cooling, electronic devices, lighting systems. This electric energy consumption was $42 \%$ of the total in 2005 and it is expected to reach more than the $50 \%$ by 2030 [1].

Thus, it is mandatory to change the approach in the building design and usage to reduce energy consumption and emissions, always keeping in mind the economic aspects of the suitability of the investment.

In this process is also important to maintain the same target of internal comfort conditions inside the building. In fact, it is not acceptable, for a building, to fulfil the near zero energy target deteriorating the indoor thermal comfort, even if the selected solutions are economically convenient [2]. On the contrary, it is better to choose more smart even if expensive solutions.

The correct approach is a comprehensive energy analysis of the whole building, considering both envelope and plants, leading to a reduction of the energy consumption up to $50 \%$ in offices [3].

To address the retrofit interventions, the first step is to analyze the present operating conditions of the building, evaluating the energy request for heating and cooling. To this aim, Aksoezen et al. [4] proposed a rough estimate of the energy consumptions based on the age of construction of the building, to allow fast and easy analyses of the existing building stock.

To calculate the energy demand of a building in an accurate way, a dynamic (transient) approach produces better results in term of accuracy because the inertia properties of the structure are taken into account. Vollaro et al. [5] presented a case study for a building located in an historical city in central Italy for which simulations are compared with in situ measurements of the thermal transmittance of the opaque walls and of the temperature field by means of a thermographic camera. In the comparison, a very good agreement is achieved only if a dynamic approach is applied. Once evaluated the energy needs of a building, it is necessary to select proper technological solution able to fulfil energy saving. On this research topic, many studies have been developed in the recent years.

Some retrofit interventions are addressed to the envelope, to reduce the energy needs of the building also by optimizing the contribution of the solar gains. Some other technological solutions are finalized to the better use of energy, by increasing the efficiency of conversion plants. 
In a study based on Energy Plus (E-Plus,[6]) simulations, Boyano et al. [7] proposed a procedure to detect the best arrangement of retrofit interventions to increase the energy saving of the analyzed building. Moreover, they suggested high insulation of the building for sites with cold or medium climate, while analyzing case by case in warm climatic conditions.

Recently, Wu et al. [8] proposed a multi-objective neighbourhood field optimization (MONFO) algorithm to select the best combination of retrofit solutions for a building, taking also into account the cost due to the maintenance of the selected technologies. These costs have a relevant influence in the evaluation of sustainability of the investment from the economic point of view, influencing in a decisive way also the choice of the different retrofit packages.

The present paper proposes a methodology to help the choice of the different technical solutions in the retrofit process of a building. Different innovative retrofit technologies have been considered, and applied according to different intervention package combinations. The building selected for the analysis has been dynamic simulated by using the software Energy Plus. The results for the different retrofit solutions have been compared in terms of reduction of energy consumption with respect to the base case and in terms of simple payback period of the financial investments.

\section{METHODOLOGY}

The aim of the present paper is to offer a methodology to simplify the selection of the retrofit interventions for an existing building.

The first step of the process is to collect as much as possible accurate information about the building structure (e.g. geometry, orientation, materials, stratigraphy) and the operative conditions of each internal zone (e.g. temperature setpoints, air changes per hour, internal gains, lighting, use of electrical equipment).

The building is then modelled by means the software E-Plus software, a worldwide known open software available online free of charge [6]. The hourly simulations first analyze the building in its initial configuration, allowing to correctly evaluate the energy needs for heating, cooling and for electric usages. In such a way the present "base scenario" is obtained.

The following step is to define some Key Performance Indicators (KPIs) in order to identify the area of intervention for energy saving, considering the building envelope, the lighting system, the technical equipment. For each KPI a benchmark value is proposed, based on different reference sources, as for example the Italian regulations in terms of building energy efficiency [9].

The results obtained from the simulation of the base case scenario are then compared to new building configurations in terms of KPI benchmark values, and the intervention areas producing the most meaningful effects are selected. Based on this analysis, a series of technologies eligible for the retrofit action are then selected and grouped in different Intervention Packages (IPs).

Each IP configuration is again simulated with E-Plus, maintaining the internal comfort levels and operating conditions in terms of temperature and illuminance. The simulations provide different energy needs for heating, cooling, lighting and general electric usage.

Finally, the results for each IP are compared with the base case scenario in term of energy saving and Simply Pay Back Period (SPB) in order to identify the better retrofit package.

In this paper the above procedure is applied to a case study related to an existing large building in the city of Genova, Italy: Monoblocco pavilion of the San Martino hospital. This choice is related to the fact that hospitals are high energy demanding buildings, especially in term of electric energy due to the extensive use of medical equipment and also to the request of cooling and air conditioning all year long.

The case study is part of a European project that aims to promote the retrofit of existing public building in order to help reaching Horizon 20-20 energy savings objectives. The project name is Affordable and Adaptable Public Building through Energy Efficient Retrofitting (A2PBEER) [10]. The project includes buildings different in shapes, size, intended use, geographical position and year of construction. In this way, it is possible to prove that the methodology is widely applicable to a vast variety of building types.

\section{E-PLUS MODEL IMPLEMENTATION}

\subsection{Geometry Drawing}

The built-up process of the building 3D geometry started with importing in Google Sketch Up the CAD plan view of the single floors.

Then, the raw model is manipulated with Openstudio plug-in for Sketch Up: this program is a graphical interface that greatly simplify the creation of the Energy Plus input files (idffile). Here, several different tuning of the model are carried out, for example the material selection to every surface as well as the definition of boundary conditions for all the surfaces (external wall, interior partition, floor, basement slab, roof) in order to evaluate the heat transfer rates at each surface and the global energy balance of the building. 
Table 1. Glazed surface window to wall ratio

\begin{tabular}{lcc}
\cline { 2 - 3 } & North façade & South façade \\
\hline Wall Area $\left[\mathrm{m}^{2}\right]$ & 17.94 & 12.47 \\
\hline Window Area $\left[\mathrm{m}^{2}\right]$ & 9.59 & 9.20 \\
\hline Windows/Wall ratio [-] & 0.44 & 0.54 \\
\hline
\end{tabular}

Table 2. Glazed surfaces main properties

\begin{tabular}{lcc}
\cline { 2 - 3 } Window type & $\begin{array}{c}\text { Transmittance } \\
{\left[\mathbf{W} / \mathbf{m}^{2} \mathbf{K}\right]}\end{array}$ & SHGC \\
\hline Low-e glazing 33/12/44 Antelio & 1.9 & 0.39 \\
\hline 33/15/33 two layer glazing system & 3.3 & 0.34 \\
\hline 70' simple glazing 4 mm & 5.8 & 0.39 \\
\hline
\end{tabular}

\subsection{Glazed surfaces}

The glazed surfaces are included into the model by simplifying the geometry with the definition of a window to wall ratio (WWR) (Table 1), which was introduced in Openstudio using a built-in script.

To evaluate the glazed surface main properties (total transmittance, light visible transmissivity and Solar Heat Gain Coefficient, SHGC), data have been retrieved in this study from software WINDOW 6, a program developed by Lawrence Berkley National Laboratory (LBNL) available online free of charge [11].

This software relies on rich library with data related to many commercially available window products. The above program also allows to completely define the geometry and materials of the window (thickness and number of glass panels, gas filling the gaps, frame, dividers and shading devices) and to obtain its overall properties. These properties for three types of window considered in this study are summarized in Table 2 .

\subsection{Shadowing Surfaces}

The present model takes also into account the external shading surfaces and the balconies that modify the solar gain contribution on the building during the day depending on the different surface orientation.

This aspect has a great influence in the global energy balance of the building. In fact, the solar gains act negatively during summer when the presence of the shadowing surfaces is positive; on the contrary, the solar gains are helpful during winter, reducing the heating load of the building.

In addition, the window blinds are implemented on the glazed surfaces, controlled by means of a schedule depending on the solar radiation incident on the window surface: if the radiation intensity exceeds a threshold value, the blinds are unrolled down.

\subsection{Thermal Bridge Analysis}

In the definition of the energy balance of a building, neglecting the contribution of thermal bridges can lead to relevant errors, especially if the structure presents balconies and overhangs, which is the case for the building under consideration in the present study. Moreover, the contribution to the heat losses due to thermal bridges gains more relevance when considering high level insulation buildings compared with older dwellings. The reference international standards dealing with this technical aspect are the UNI EN ISO 14683:2008 [12] and the UNI EN ISO 10211:2005 [13] that suggest the traditional simplified procedure based on the concept of the linear thermal transmittance.

More recently, in the building thermal analysis finalized to the evaluation of actual energy consumptions and to the selection of suitable retrofitting interventions for their reduction, a dynamic approach has been introduced, taking into account also the thermal inertia of the different building elements. In this framework, many studies have been devoted also to the transient analysis of the thermal bridges behavior [14,15,16,17].

However, according to the international standard UNI EN ISO 13786:1999 [18], "Thermal bridges generally used in building components do not affect the dynamic thermal characteristics significantly, and may be ignored.' Moreover, some software for the dynamic thermal analysis of building as TRNSYS [19] adopt in the thermal bridges analysis the steady state approach with the definition of linear thermal transmittances.

Unfortunately E-Plus cannot directly model the thermal bridges associate to a structure and hence a correction of the wall overall transmittance is necessary. Based on the previous considerations, a stationary approach has been adopted, according to the following methodology. 
The analysis starts by evaluating the total heat transfer through a structure according to the UNI EN ISO 14683:2008 [12]:

$\dot{Q}_{\text {tot }}=U_{\text {wall }} \cdot A_{\text {wall }} \cdot \Delta T+\sum_{i=1}^{n} \varphi_{i} L_{i} \Delta T$

where:

- $U_{\text {wall }}$ is the wall total transmittance $\left[\mathrm{W} / \mathrm{m}^{2} \mathrm{~K}\right]$;

- $A_{\text {wall }}$ is the wall area without windows $\left[\mathrm{m}^{2}\right]$;

- $\Delta T$ is the temperature difference between internal and external air [K];

- $\varphi_{\mathrm{i}}$ is the linear thermal transmittance of the $\mathrm{i}$-th thermal bridge $[\mathrm{W} / \mathrm{mK}]$;

- $\quad L_{\mathrm{i}}$ is the $\mathrm{i}$-th thermal bridge length $[\mathrm{m}]$.

The linear thermal transmittances for several types of thermal bridges are reported in UNI EN ISO 14683:2008 [12], as a function of the different wall stratigraphy.

On the contrary, for the calculation of the window thermal bridges this study refers to the values provided by the software WINDOW 6.

Finally, from the knowledge of the total heat transfer through a structure $Q_{\text {tot }}$, it is possible to define a fictitiously increased thermal transmittance of the structure $U^{*}$ wall to take into account the thermal bridge contribution:

$U_{\text {wall }}^{*}=\frac{\dot{Q}_{\text {tot }}}{A_{\text {wall }}}$

In the Energy Plus model, the thermal conductivity of one of the conductive layers of the composite wall of the module is then properly increased.

\subsubsection{Example of analysis for the south façade}

It is necessary to first identify a basic modular element of the façade (Figure 1) to analyze the thermal bridge effects for it and then reproduce them for all the modules the whole surface.

For the module, the wall presents the following stratigraphy, from external to internal side:

- External painting;

- $\quad$ Plaster (15 mm);

- Hollow bricks $(250 \times 100 \times 250 \mathrm{~mm})$;

- $\quad$ Air gap (100 mm);

- $\quad$ Hollow bricks $(250 \times 100 \times 250 \mathrm{~mm})$;

- $\quad$ Plaster (15 mm);

- Internal painting.

Then, one calculates the wall transmittance $U_{\text {wall }}\left[\mathrm{W} / \mathrm{m}^{2} \mathrm{~K}\right]$ by means of the approach of the thermal resistances $\left[\mathrm{m}^{2}\right.$ $\mathrm{K} / \mathrm{W}]$ :

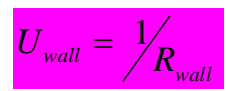

Considering the contributions of the different layers:

$R_{\text {wall }}=R_{s, \text { int }}+\left(2 \cdot R_{\text {plaster }}+R_{\text {bricks }}+R_{\text {tot }, \text { air }}+R_{\text {concrete }}\right)+R_{s, \text { ext }}$

where:

- $R_{s, i n t}$ is the effective internal thermal resistance $\left[\mathrm{m}^{2} \mathrm{~K} / \mathrm{W}\right]$;

- $R_{\text {plaster }}$ is the conductive thermal resistance of the plaster $\left[\mathrm{m}^{2} \mathrm{~K} / \mathrm{W}\right]$;

- $R_{\text {bricks }}$ is the conductive resistances of bricks $\left[\mathrm{m}^{2} \mathrm{~K} / \mathrm{W}\right]$

- $R_{\text {concrete }}$ is the conductive resistances of concrete $\left[\mathrm{m}^{2} \mathrm{~K} / \mathrm{W}\right]$;

- $R_{\text {tot,air }}$ is the total thermal resistance of the air gap, including the convective and radiative contributions $\left[\mathrm{m}^{2}\right.$ $\mathrm{K} / \mathrm{W}]$;

- $\quad R_{s, \text { ext }}$ is the effective external thermal resistance $\left[\mathrm{m}^{2} \mathrm{~K} / \mathrm{W}\right]$;

UNI EN ISO 6946:2008 [20] provides $R_{s, i n t}$ and $R_{s, e x t}$ reference values for specified inner and outdoor conditions. The total thermal resistance of the air gap $R_{t o t, a i r}$ can be again calculated according to UNI EN ISO 6946:2008 [20]:

$$
R_{t o t, a i r}=\frac{1}{h_{a}+h_{r}}
$$


Here $h_{a}$ is the conductive/convective coefficient and, for an air gap with thickness $d$ [m], it can be calculated as:

$h_{a}=\max \left\{1.25, \frac{0.025}{d}\right\}$

$h_{r}$ is the radiative coefficient, calculated as:

$h_{r}=h_{r, 0} \cdot C_{s}$

where:

$h_{r, 0}$ is the black body radiative coefficient, function of temperature (Table 3);

Table 3. Black body radiative coefficient for air gaps

\begin{tabular}{cc}
\cline { 2 - 2 } Temperature $\left[{ }^{\circ} \mathbf{C}\right]$ & $\mathbf{h}_{\mathbf{r}, \mathbf{0}}\left[\mathbf{W m}^{-\mathbf{2}} \mathbf{K}^{-\mathbf{1}}\right]$ \\
\hline-10 & 4.1 \\
\hline 0 & 4.6 \\
\hline 10 & 5.1 \\
\hline 20 & 5.7 \\
\hline 30 & 6.3 \\
\hline
\end{tabular}

$C_{\varepsilon}$ is the correction coefficient taking into account the emissivities of the two surfaces constituting the air gap, $\varepsilon_{1}$ and $\varepsilon_{2}$, respectively:

$C_{s}=\frac{1}{1 / \varepsilon_{1}+1 / \varepsilon_{2}-1}$

Considering then the linear thermal transmittances for the different thermal bridges, it is finally possible to evaluate the increased thermal transmittance of the structure $U^{*}$ wall.

Table 4 compares the values of the wall transmittance without and with considering the thermal bridges effect for both the north and the south façade.

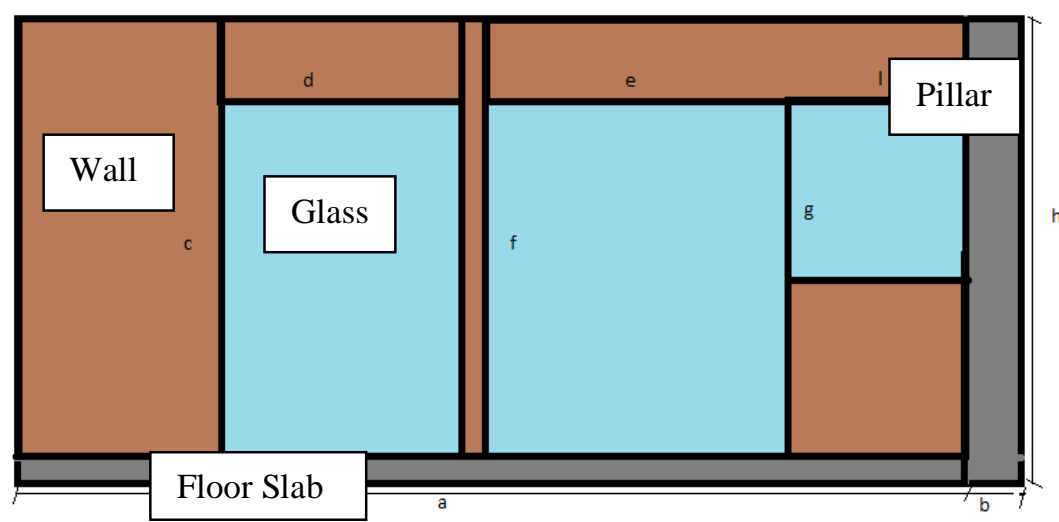

Figure 1. South façade repetitive modular element

Table 4. North and South façade wall transmittance without and with thermal bridge contributions

\begin{tabular}{lcc}
\cline { 2 - 3 } Transmittance $\left[\mathbf{W} / \mathbf{m}^{2} \mathbf{K}\right]$ & $\begin{array}{c}\text { North } \\
\text { Façade }\end{array}$ & $\begin{array}{c}\text { South } \\
\text { Façade }\end{array}$ \\
\hline Without thermal bridges $U_{\text {wall }}$ & 1.37 & 1.09 \\
\hline With thermal bridges $U_{\text {wall }}^{*}$ & 1.71 & 2.15 \\
\hline
\end{tabular}


Table 5. Temperature set points

\begin{tabular}{|c|c|c|}
\hline & Summer & Winter \\
\hline Operating Room & $22-26^{\circ} \mathrm{C}$ & $22-26^{\circ} \mathrm{C}$ \\
\hline Preparation and Post Anaesthesia & $26 \pm 1{ }^{\circ} \mathrm{C}$ & $24 \pm 1{ }^{\circ} \mathrm{C}$ \\
\hline $\begin{array}{l}\text { Reanimation and Intensive Care } \\
\text { Unit }\end{array}$ & $24 \pm 1{ }^{\circ} \mathrm{C}$ & $24 \pm 1{ }^{\circ} \mathrm{C}$ \\
\hline TAC & $26 \pm 1{ }^{\circ} \mathrm{C}$ & $24 \pm 1^{\circ} \mathrm{C}$ \\
\hline Radiology & $26 \pm 1{ }^{\circ} \mathrm{C}$ & $24 \pm 1{ }^{\circ} \mathrm{C}$ \\
\hline Dialysis & $28 \pm 1{ }^{\circ} \mathrm{C}$ & $24 \pm 1{ }^{\circ} \mathrm{C}$ \\
\hline Laboratory & $26 \pm 1^{\circ} \mathrm{C}$ & $20 \pm 1{ }^{\circ} \mathrm{C}$ \\
\hline Dressing Rooms & $28 \pm 1^{\circ} \mathrm{C}$ & $22 \pm 1{ }^{\circ} \mathrm{C}$ \\
\hline Patience Rooms & $26 \pm 1{ }^{\circ} \mathrm{C}$ & $22 \pm 1{ }^{\circ} \mathrm{C}$ \\
\hline Offices, Clinic, Class room & $26 \pm 1^{\circ} \mathrm{C}$ & $20 \pm 1{ }^{\circ} \mathrm{C}$ \\
\hline Pharmacy & $26 \pm 1^{\circ} \mathrm{C}$ & $20 \pm 1{ }^{\circ} \mathrm{C}$ \\
\hline Sterilization & $24 \pm 1{ }^{\circ} \mathrm{C}$ & $20 \pm 1{ }^{\circ} \mathrm{C}$ \\
\hline
\end{tabular}

Table 6. Minimum Air Changes per Hour

\begin{tabular}{lc}
\hline Operating Room & $15[\mathrm{ach}]$ \\
\hline Preparation and Post Anaesthesia & $6[\mathrm{ach}]$ \\
\hline Reanimation and Intensive Care Unit & $12[\mathrm{ach}]$ \\
\hline TAC & $10[\mathrm{ach}]$ \\
\hline Radiology & $6[\mathrm{ach}]$ \\
\hline Dialysis & 6 [ach] \\
\hline Laboratory & $6[\mathrm{ach}]$ \\
\hline Dressing Rooms & $2[\mathrm{ach}]$ \\
\hline Patience Rooms & $2[\mathrm{ach}]$ \\
\hline Offices, Clinic, Class room & $2[\mathrm{ach}]$ \\
\hline Corridors & $1[\mathrm{ach}]$ \\
\hline Pharmacy & $6[\mathrm{ach}]$ \\
\hline Sterilization & $10[\mathrm{ach}]$ \\
\hline
\end{tabular}

\subsection{Internal Energy Gains Modelling}

In the evaluation of the energy balance of the building, it is mandatory to take into account the building internal gains. In fact, all the heating contributions (sensible or latent) that come from people, lighting and electrical equipment, can significantly reduce the thermal loads during winter and increase them during summer.

\subsection{Thermal Zones Assignment}

A further step in the modelling of the building is the identification of the different thermal zones, according to ISO 13790:2008 standard [20]. These zones differ in temperature set-points (Table 2), air changes per hour (ach) (Table 3), and internal gains. 


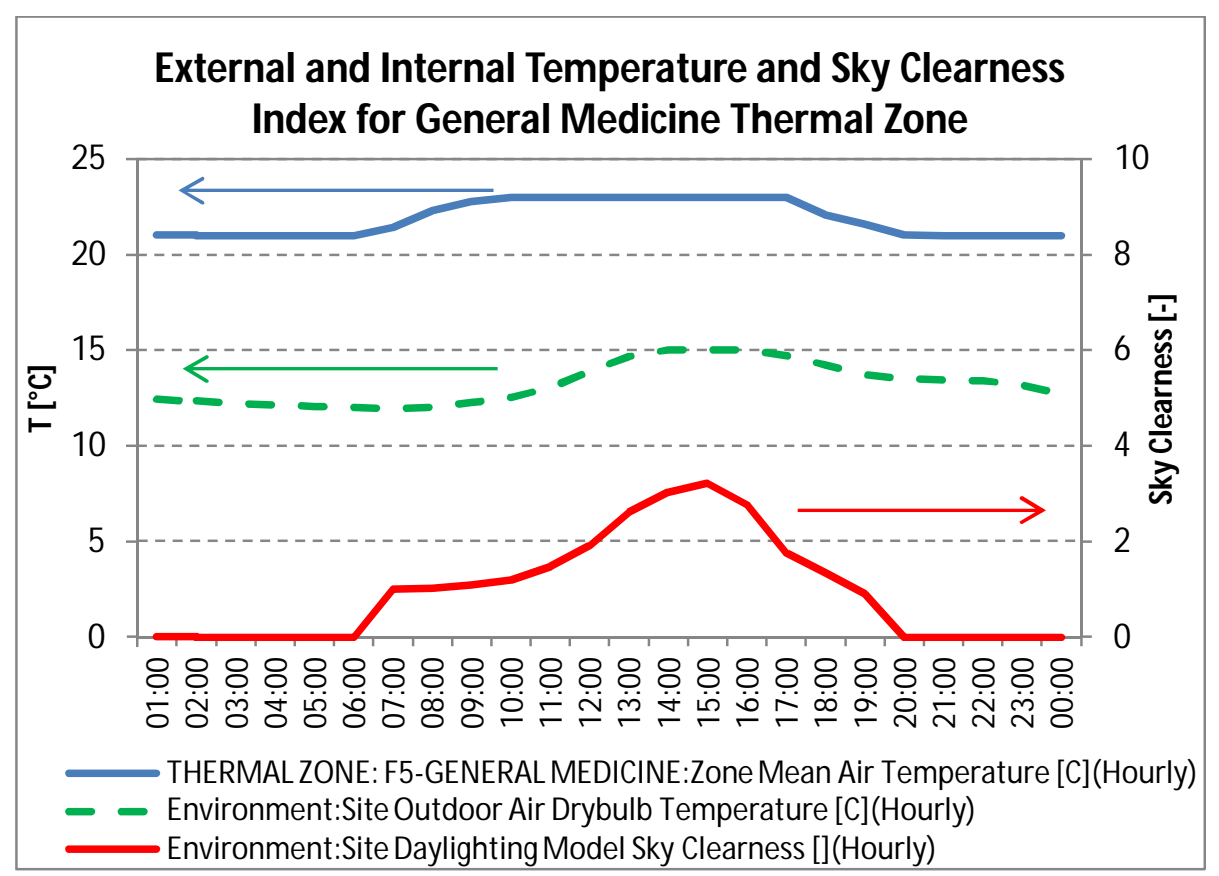

Figure 2. Base case: General Medicine Thermal Zone daily Sky Clearness Index, Internal and External Temperature for April 6th.

\subsection{Weather Conditions}

The weather conditions necessarily affect the energy balance of the building. The information about the site where the building is placed are considered into the model by means of the data included in the weather file: its altitude, latitude and longitude, data hourly series related to temperature, humidity, wind speed, solar radiation, precipitation and other important climatic parameters.

Figure 2 shows and example of daily internal temperature trend together with the external temperature as well as the sky clearness index.

\subsection{HVAC modelling}

In the Energy Plus model of the building, the HVAC system has been greatly simplified by using the "Ideal Loads" option.

According to this option, the "ideal" unit is able to reach desired conditions in terms of temperature (see Table 5) as well as air changes per hours (see Table 6). To this aim, it mixes air at the zone exhaust conditions with a specified amount of outdoor air and then adds or removes heat and moisture at $100 \%$ efficiency.

The main outputs of the defined model are basically the annual energy consumptions of the whole building. In particular, the model evaluates the energy spent by the HVAC system in order to maintain internal comfort setpoints.

In addition, also electric consumptions of the internal lighting system and of the electrical equipment plugged inside the zones are estimated.

\subsection{Base case scenario results}

First, the base case scenario is simulated: the results are summarized in Table 7, aggregated on annual basis, while Figure 3 presents the monthly heating and cooling loads.

In the zones with particular lights or electrical medical devices (i.e. radiology, operating rooms), cooling is required also during the heating season because of the high internal gains.

As an example, Figure 4 reports the hourly energy needs for the "Radiology" thermal zone during 24 hours, for April $6^{\text {th }}$. 
Table 7. Base case scenario annual total energy required

\begin{tabular}{ll}
\hline Cooling & $3554[\mathrm{MWh} / \mathrm{y}]$ \\
\hline Heating & $6846[\mathrm{MWh} / \mathrm{y}]$ \\
\hline Interior Lighting & $2723[\mathrm{MWh} / \mathrm{y}]$ \\
\hline Interior Equipment & $5337[\mathrm{MWh} / \mathrm{y}]$ \\
\hline
\end{tabular}

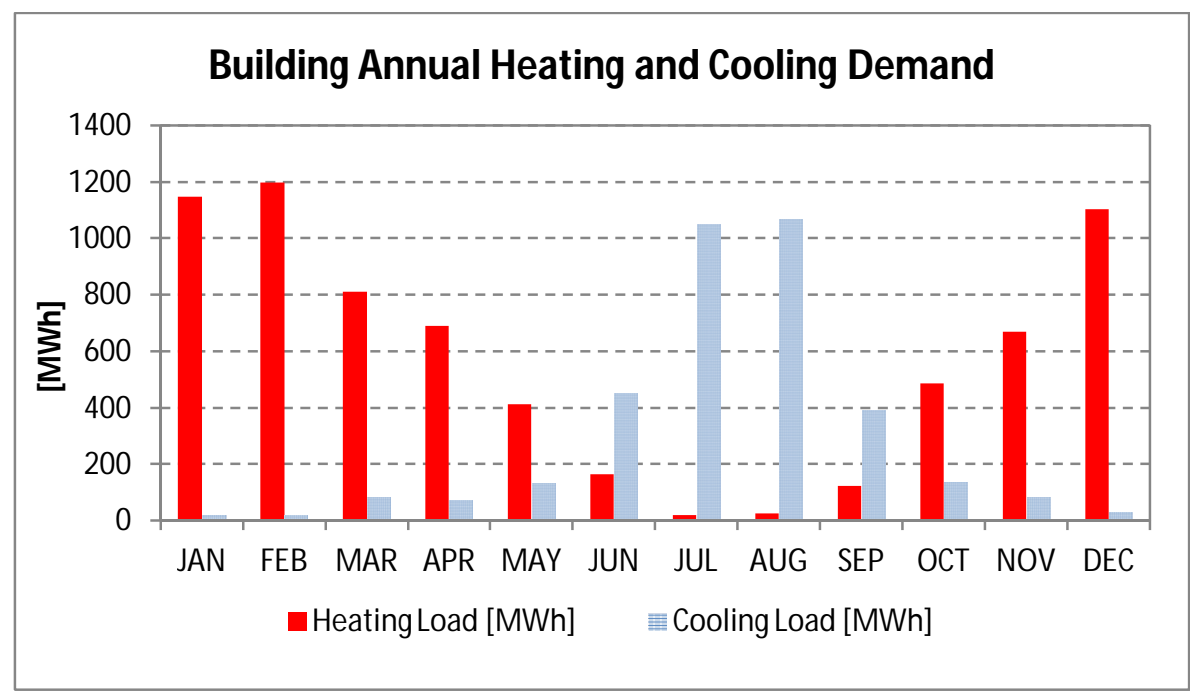

Figure 2. Base case: annual heating and cooling loads.

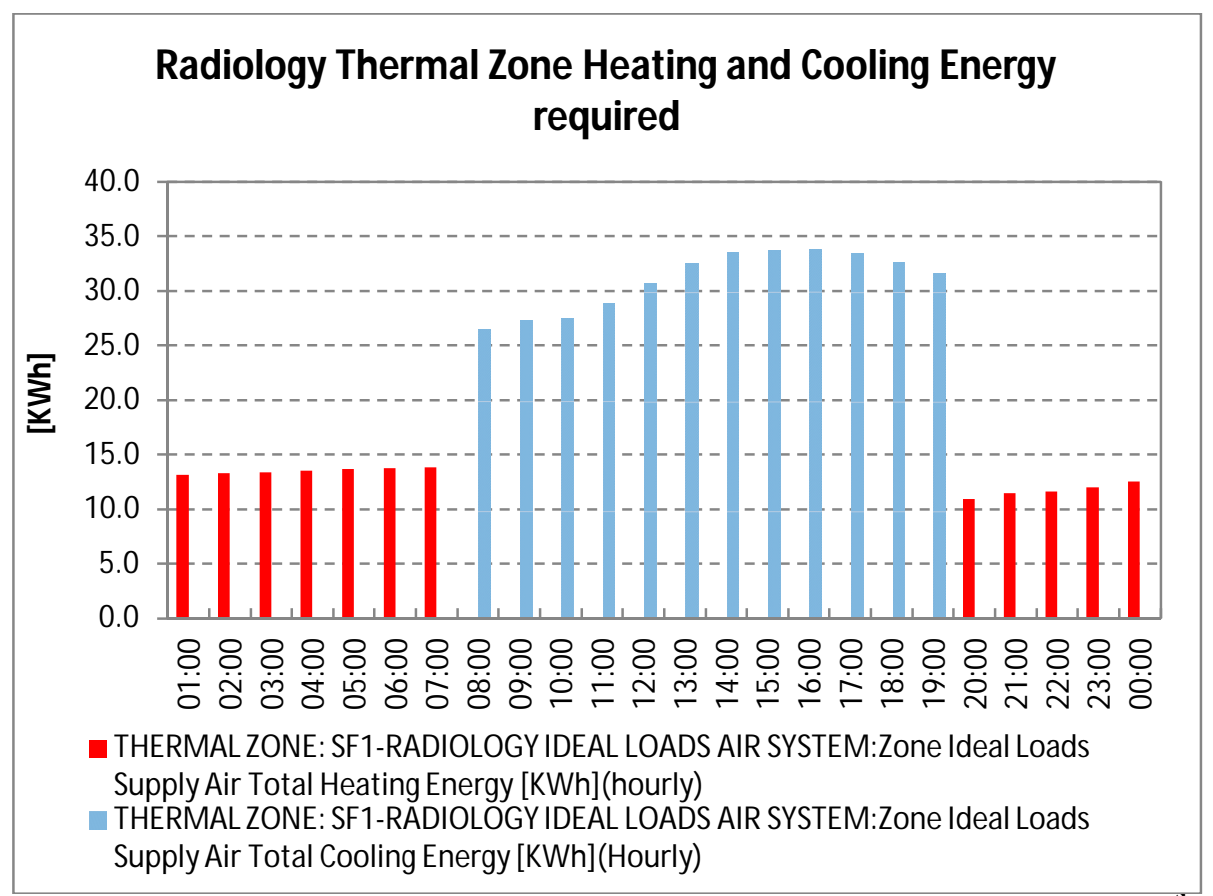

Figure 3. Base case: Radiology Thermal Zone daily energy demand for April $6^{\text {th }}$.

\section{KEY PERFORMANCE INDICATORS (KPIs)}

In the retrofit process of a building, it is mandatory to properly select the technologies eligible for the retrofit interventions to improve the building energy performance.

Thus, a list of Key Performance Indicators (KPIs) has been compiled to successfully choose the intervention areas. Different types of KPIs have to be considered, related to the envelope, the lighting systems and the operating conditions. The list of the analysed KPIs is summarized in Table 8. 
Table 8. KPIs identification

\begin{tabular}{c}
\hline Building structures \\
\hline Thermal transmittance of opaque structures, \\
$U_{\text {opaque }}\left[\mathrm{W} / \mathrm{m}^{2} \mathrm{~K}\right]$ \\
\hline Thermal transmittance of glazed surfaces, $U_{\text {glazed }}$ \\
{$\left[\mathrm{W} / \mathrm{m}^{2} \mathrm{~K}\right]$} \\
\hline Mean global heat transfer coefficient, $U_{\text {tot }}$ \\
{$\left[\mathrm{W} / \mathrm{m}^{2} \mathrm{~K}\right]$} \\
\hline Lighting system \\
\hline Lighting efficiency, Energy Efficiency Index, \\
$E E I[-]$ \\
\hline Actual usage power density, Lighting Energy \\
Numeric Indicator, $L E N I\left[\mathrm{kWh} / \mathrm{m}^{2} \mathrm{y}\right]$ \\
\hline Building energy use \\
\hline Annual heating energy need per unit volume, \\
$E_{\text {heating }}\left[\mathrm{kWh} / \mathrm{m}^{3} \mathrm{y}\right]$ \\
\hline Annual cooling energy need per unit volume, \\
$E_{\text {cooling }}\left[\mathrm{kWh} / \mathrm{m}^{3} \mathrm{y}\right]$ \\
\hline Energy cost \\
\hline Simple Pay Back Period, SPB $[\mathrm{y}]$ \\
\hline
\end{tabular}

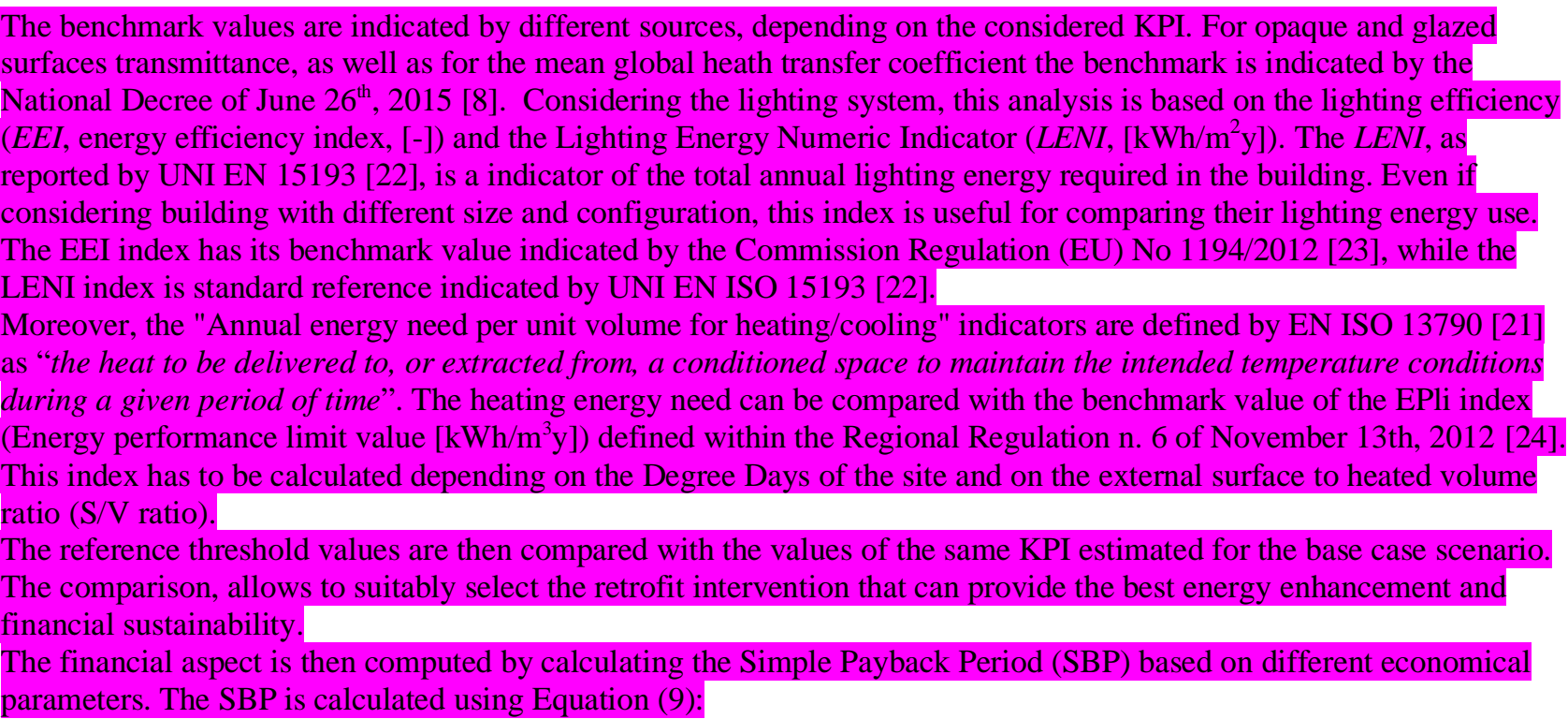

$S B P=\frac{\text { Initial Investment Costs }}{A_{s} \cdot \text { Tariff }+A_{p} \text { RES } \cdot \text { Tariff }+\Delta O M}$

where:

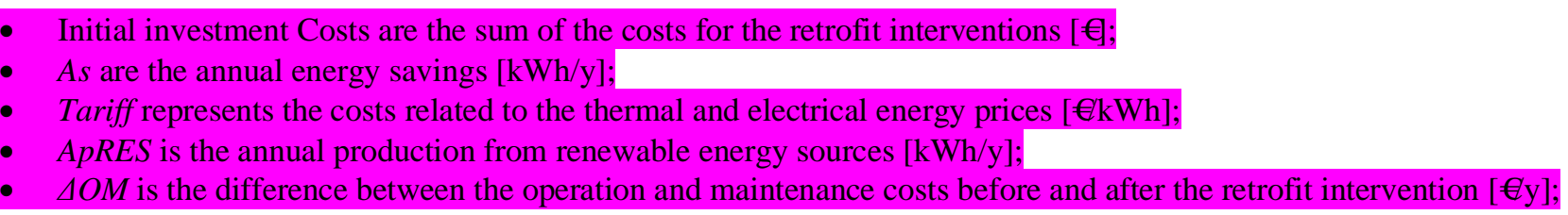

These reference threshold values are then compared with the values of the same KPI estimated for the base case scenario. The comparison, presented here in Table 9, allows to suitably select the retrofit intervention that can provide the best energy enhancement and financial sustainability. 
Table 9. KPIs comparison for the base case, retrofit scenarios and benchmark values

\begin{tabular}{|c|c|c|c|c|c|c|}
\hline \multirow{2}{*}{ KPIs } & \multirow{2}{*}{$\begin{array}{l}\text { Benchmark } \\
\text { values }\end{array}$} & \multirow{2}{*}{ Base case } & \multicolumn{4}{|c|}{ Retrofitted cases } \\
\hline & & & $\begin{array}{c}\text { IP1: } \\
\text { F+W+L }\end{array}$ & IP2: $\mathbf{F}+\mathbf{L}$ & IP3: W+L & IP4: $\mathbf{F}+W$ \\
\hline \multicolumn{7}{|c|}{ Building structures } \\
\hline $\begin{array}{c}\text { Façade } 1 \\
\text { (North - East - } \\
\text { West) } \\
\end{array}$ & \multirow[t]{2}{*}{0.36} & 1.71 & $0.1-0.5$ & $0.1-0.5$ & 1.71 & $0.1-0.5$ \\
\hline K] $\frac{\text { Façade } 2}{\text { (South) }}$ & & 2.15 & $0.1-0.5$ & $0.1-0.5$ & 2.15 & $0.1-0.5$ \\
\hline $\begin{array}{cc}\begin{array}{c}U_{\text {glazed }} \\
{\left[\mathrm{W} / \mathrm{m}^{2} \mathrm{~K}\right]}\end{array} & \begin{array}{c}\text { Fenestration 3 } \\
\text { simple glazing } 4 \\
{[\mathrm{~mm}]}\end{array} \\
\end{array}$ & 2.4 & 5.8 & $1-2$ & 5.8 & $1-2$ & $1-2$ \\
\hline$U_{t o t}\left[\mathrm{~W} / \mathrm{m}^{2} \mathrm{~K}\right]$ & 0.68 & 2.74 & $1-2$ & $1-2$ & $2-3$ & $1-2$ \\
\hline \multicolumn{7}{|c|}{ Lighting system } \\
\hline$E E I[-]$ & $<0.50$ & - & $\begin{array}{c}\text { Class "A" } \\
<0.4\end{array}$ & $\begin{array}{c}\text { Class "A" } \\
<0.4\end{array}$ & $\begin{array}{c}\text { Class "A" } \\
<0.4\end{array}$ & - \\
\hline LENI $\left[\mathrm{kWh} / \mathrm{m}^{2} \mathrm{y}\right]$ & 70.6 & 54.02 & $10-12$ & $10-12$ & $10-12$ & 54.02 \\
\hline \multicolumn{7}{|c|}{ Building energy use } \\
\hline$E_{\text {heating }}\left[\mathrm{kWh} / \mathrm{m}^{3} \mathrm{y}\right]$ & 6.18 & 45.93 & $43-45$ & $45-48$ & $40-43$ & $35-40$ \\
\hline$E_{\text {cooling }}\left[\mathrm{kWh} / \mathrm{m}^{3} \mathrm{y}\right]$ & - & 23.84 & $13-15$ & $15-17$ & $22-24$ & $15-17$ \\
\hline \multicolumn{7}{|c|}{ Energy cost } \\
\hline SPB [years] & - & - & 14.5 & 10 & 9.3 & 27.4 \\
\hline
\end{tabular}

\section{SELECTED RETROFIT TECHNOLOGIES}

In this analysis, three innovative technologies have been selected:

- Façade: super insulated and ventilated Void Insulated Panels (VIP);

- Windows: smart rotating windows with sealing hydraulic gasket;

- Lighting system: Intelligent Lighting Control (ILC) LED and solar light optical fibre system.

\subsection{VIP Façade}

When working on the retrofit of an existing building, frequently the intervention area is the envelope, and in particular the attention is addressed to good insulation of the façades. To reach the reference values recommended by the standards for the thermal transmittance of opaque structures, the use of classic materials can lead to some problems. In fact, the usual values of the thermal conductivity of these materials impose high insulation thicknesses.

For this reason, in some cases to preserve the historic and aesthetic value of the building, insulation must be installed on the inner side of the façade, with possible resulting problems of moisture formation, superficial and interstitial condensation.

At the expected thermal resistance, the thickness of VIP panels is much smaller $(30 \mathrm{~mm})$ because of its special insulation due to its innovative technology (transmittance $U_{1 D}<0.2 \mathrm{~W} / \mathrm{m}^{2} \mathrm{~K}$ ) [25]. The installation of the VIP panels at the outside of the floor concrete slabs also reduces the thermal bridges at the different floors [25].

For the present analysis, VIP panels developed by the manufacturer Isoleika have been considered. They are composed by the following multilayer structure (material and thickness of each layer):

- Rubber laminated $(3+3 \mathrm{~mm})$ and VIP insulation $(30 \mathrm{~mm})$ adhered to existing wall; 
- Polythene vapour barrier;

- Mineral wool insulation (40mm) within free standing aluminium vertical profiles $(46 \mathrm{~mm})$;

- Oriented strand board $(9 \mathrm{~mm})$;

- Plasterboard (15mm).

\subsection{Smart Rotating Windows}

Windows are a critical point for the efficiency of buildings.

Thermal transmittance of glazed surfaces is often very high, also due to the relevant contribution of the thermal bridging of the window frames.

Additionally, glazed surfaces easily transmit incoming solar radiation (high SHGC, Table 2), leading to green-house effect inside rooms, useful during winter but negative in summer.

A common way to reduce the transmittance of windows is to use multiple glass layers and proper gas fillers between panes; in addition it is possible to reduce the solar gains by applying special film coatings with good radiative properties to the glass, beneficial in summer but not always during the cold months.

Smart rotating windows are innovative because they are constituted by a glazed surface equipped with a low emissivity $\varepsilon$ (high reflectivity) coating. The entire window can rotate around hinges to switch between summer/winter configurations, to expose the coated side to the exterior during the summer period. In this way is possible to minimize or maximize solar gains, depending on the season climatic conditions [25].

The rotating frame of the window is hydraulically sealed by a non-freezing liquid, which can be discharged to rotate the sash. This special gasket system is very effective at maintaining the room hermetically closed, reducing the infiltration from the external environment.

\subsection{ILC LED and Solar Light Optical Fibre system}

Energy consumptions related to lighting are relevant (about $11 \%$ of energy use in residential buildings and $18 \%$ in commercial buildings [26]). Thus, solutions to reduce this contribution are useful for the saving of energy and money. Moreover, it is mandatory to keep the same comfort level inside the buildings, preferring the use of daylight, in line with the current and coming regulations for energy efficiency in buildings.

The innovative lighting system proposed by Toshiba is represented in Figure 5. It captures and distributes sunlight inside the building using proper diffusers. The system is equipped by presence sensors in addition to sensors measuring the present natural light intensity. When daylight is not satisfactory for the illumination requirements, an integration is provided by high efficiency LEDs (ILC - Intelligent Lighting Control).

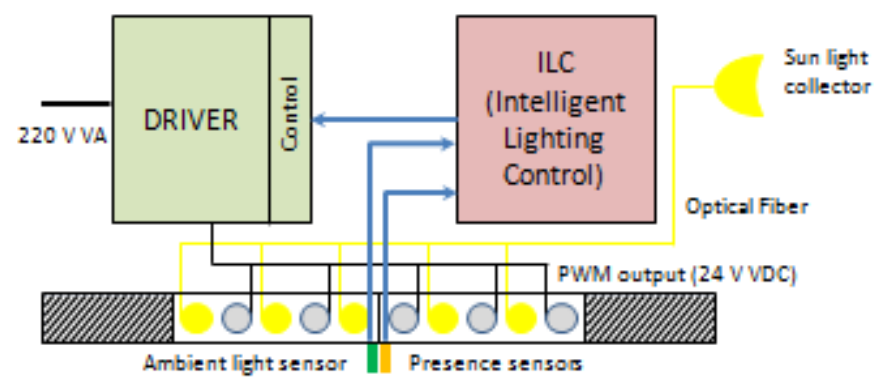

Figure 5. Smart Lighting System schematic

\subsection{Selected Intervention Packages (IPs)}

Synergies between different interventions have been investigated organizing technical solutions into a set of Intervention Packages (IPs):

- IP1 - Void Insulated Panels (VIP) façade, smart windows and LED system;

- IP2 - VIP façade and LED system;

- IP3 - Smart windows and LED system;

- IP4 - Smart windows and VIP façade.

The results of the Energy Plus simulations for the different retrofit scenarios have been compared against the base case results to estimate the energy savings. The economic aspects are considered by calculating the Simple Pay Back Period (SPB) for each investment, to evaluate the best retrofit solution also from this point of view. 


\section{SIMULATION RESULTS}

\subsection{Results for IP1: VIP façade, smart windows and LED system}

Table 10 presents a list of the energy demands after the building retrofit with IP1 action, aggregated on annual basis. Annual energy savings can be obtained comparing Table 10 and Table 7:

- Heating [MWh/y]: 190

- Cooling [MWh/y]: 1329

- Interior Lighting [MWh/y]: 2125

For the present building, the best improvement is linked to the retrofit of the lighting system. This is related to the very high efficiency of the proposed solution with respect to the existing illumination system. The lighting system substitution also greatly reduces the internal gains related to building lighting.

Considering the HVAC system, cooling energy needs are reduced more than heating ones. It is important to observe that both VIP façade and smart windows interventions mostly operate on the south-facing façade, which are greatly sun exposed all year long. Thus, the IP1 intervention significantly reduces the sun-related energy gains during cooling season.

Table 10. IP1 annual total required energy

\begin{tabular}{ll}
\hline Cooling & $2249[\mathrm{MWh} / \mathrm{y}]$ \\
\hline Heating & $6761[\mathrm{MWh} / \mathrm{y}]$ \\
\hline Interior Lighting & $598[\mathrm{MWh} / \mathrm{y}]$ \\
\hline Interior Equipment & $5337[\mathrm{MWh} / \mathrm{y}]$ \\
\hline
\end{tabular}

Table 11. IP2 annual total energy required

\begin{tabular}{ll}
\hline Cooling & $2247[\mathrm{MWh} / \mathrm{y}]$ \\
\hline Heating & $7189[\mathrm{MWh} / \mathrm{y}]$ \\
\hline Interior Lighting & $598 \quad[\mathrm{MWh} / \mathrm{y}]$ \\
\hline Interior Equipment & $5337[\mathrm{MWh} / \mathrm{y}]$ \\
\hline
\end{tabular}

Table 12. IP3 annual total energy required

\begin{tabular}{ll}
\hline Cooling & $2231[\mathrm{MWh} / \mathrm{y}]$ \\
\hline Heating & $7369[\mathrm{MWh} / \mathrm{y}]$ \\
\hline Interior Lighting & $598[\mathrm{MWh} / \mathrm{y}]$ \\
\hline Interior Equipment & $5337[\mathrm{MWh} / \mathrm{y}]$ \\
\hline
\end{tabular}

Table 13. IP4 annual total energy required

\begin{tabular}{ll}
\hline Cooling & $3491[\mathrm{MWh} / \mathrm{y}]$ \\
\hline Heating & $5293[\mathrm{MWh} / \mathrm{y}]$ \\
\hline Interior Lighting & $2723[\mathrm{MWh} / \mathrm{y}]$ \\
\hline Interior Equipment & $5337[\mathrm{MWh} / \mathrm{y}]$ \\
\hline
\end{tabular}

\subsection{Results for IP2: VIP façade and LED system}

Table 11 presents the annual values of energy required from the building in case of the retrofit intervention IP2. Again, the comparison between Tables 11 and 7 leads to the evaluation of annual energy savings:

- Heating [MWh/y]: - 498

- Cooling [MWh/y]: 1117.5

- Interior Lighting [MWh/y] 2124

It is immediate to note that the heating energy demand has worsened with respect to the base case. An explanation to this can be related to the lack of heating due to the substitution of the existing fluorescent tubes. This allows a reduction in electrical consumptions but, on the other hand, an increase of the heating loads during cold periods. In fact, the lower 
heat losses through the opaque walls (which account for some $50 \%$ of the overall façade surface) are not able to balance the former contribution by the fluorescent light sources.

On the contrary, during summer the presence of VIP façade is very effective in reducing the sun energy gains through opaque surfaces.

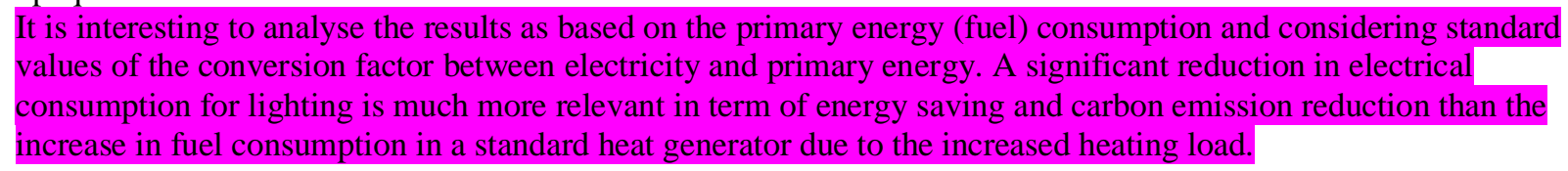

\subsection{Results for IP3: smart windows and LED system}

Comparing the results of Table 12 with the those relative to the base case scenario (Table 7), it is possible to evaluate the following annual energy saving associated with the IP3:

- Heating [MWh/y]: 463

- Cooling [MWh/y]: 1111

- Interior Lighting [MWh/y]: 2405

Generally, the energy savings are not very different from the ones obtained for IP1 scenario, except for the slightly higher savings in heating.

\subsection{Results for IP4: smart windows and VIP façade}

From Table 13, the energy savings with respect to the base case scenario (Table 7) are the following:

- Heating [MWh/y]: 930

- Cooling [MWh/y]: 1119

- Interior Lighting [MWh/y]: 0

Since there is no retrofit of the lighting system, there is no reduction for the lighting energy consumption. Moreover, the energy saving values are interesting, but given the unaltered consumption for lighting, this intervention package will hardly be a good choice for building retrofit, from the economical point of view of the investment.

\subsection{Intervention analysis: KPIs re-evaluation}

For all the simulated Intervention Packages IPs, a comparison with both the base case results and the benchmark values has been carried out (Table 9). This analysis is necessary in order to evaluate the results after the retrofit interventions. First the structures of the building envelope are considered. The retrofit with VIP panels seems to be necessary to reduce the transmittance of opaque surfaces below the threshold of the national directive values [8]. Similarly, the installation of the smart rotating windows revealed to be necessary for reducing the transmittance of the glazed surfaces below the maximum allowed values of the above national regulation. Unfortunately, the mean global heat transfer coefficient of the whole building is not acceptable for all the proposed retrofit interventions because its value is higher than the threshold one indicated by the Italian Regulation.

Considering the lighting system, the EEI (energy efficiency index) of the new LED system is compliant with the selected threshold value, recommended by the Commission Delegated Regulation (EU) No 1194/2012 [23]. Moreover, when the smart LED system is used for the retrofit, the LENI is below the benchmark value.

On the contrary, the values of the "Annual energy need for unit volume for heating", calculated for all the intervention packages, are above the benchmark values. The "Annual energy need for unit volume for cooling" has been calculated but there is no benchmark value for the comparison.

Finally the simple payback period has been calculated in order to compare the different intervention packages from an economical point of view.

\section{CONCLUSIONS}

The paper main aim is to define a methodology able to properly select and check some intervention packages composed by different retrofit solutions to be applied to an existing building in order to reduce its energy requirements. The procedure has been applied to a real case study: the Monoblocco Pavilion at the San Martino Hospital in Genova, Italy. The method is based on the dynamic simulations of the thermal behaviour of the building, carried out with the software Energy Plus. The simulations consider a base case scenario and a series of retrofit intervention packages: a comparison of the results in terms of either energy or economic point of views has been performed. 
In the following, a brief summary of the main results related to the different Intervention Packages (IPs) is presented:

- IP1: VIP facade, smart windows and LED system

The simulations show that combining all the three retrofit technologies greatly reduces the cooling energy needs, more than any other IP here considered. On the other hand, the reduced energy for lighting thanks to the LED system negatively affects the heating energy needs, which in turn are not as low as one could expect. The resulting Simple Pay Back Period (SPB) in this case is relatively high (14.5 years).

- IP2: VIP facade and LED system.

This scenario shows that the combination of VIP façade with lamps substitution gives an unexpected increase in the heating load with respect to base case. In fact, the heating needs are influenced by different contributions: the reduced energy gains due to LED lighting system, the reduced dispersion through the opaque envelope, the reduced solar gains through opaque surfaces.

An explanation could be found during night time or cloudy days when the outdoor temperature is low: while the opaque surfaces help to keep the heat inside, the existing window heat losses are not balanced by meaningful solar gains. Moreover, the LED system strongly reduces the internal gains.

On the other hand, the energy needs for cooling are lower than the case scenario values but still higher with respect to the IP1 case.

- IP3: smart windows and LED system.

Here it is clear that the use of smart windows is crucial for the energy efficiency of the building. Being located on the south façade, smart windows are primary in maximizing solar heat gains and reducing the dispersion toward the outside during the cold seasons. This effect is very important in order to balance the reduced internal gains related to LED installation.

On the contrary, the windows installation does not affect in a decisive way the energy needs for cooling. In fact, VIP panels, with their very low transmittance value, have the major impact on the cooling energy needs.

From the economic point of view, the pay-back period indicates that the IP3 represents here the best solution (9.3 years).

- IP4: smart windows and VIP facade.

This IP is the best for energy savings during the heating season and the second one with respect to the cooling aspects. However, the absence of energy saving for lighting, which accounts for more than 2000 [MWh/y], makes the this intervention far for being economically feasible. In fact, given the very high costs of the VIP panels, the SBP of the IP is really too high (27.4 years).

Finally, with reference to the particular local climate (relatively high winter external temperatures and relevant solar energy contribution during the whole year), the installation of the smart rotating windows has great benefits in terms of energy saving, giving also the overall smaller cost with respect to the other retrofit options. Moreover, considering the present illumination system, with no automatic control and with standards lamps, the installation of an innovative system is crucial to reduce the electricity consumption and to keep the retrofit action acceptable from an economic point of view. It is also important to remind that the energy market is being driven towards a kind of "electrification" also at

an European level, for this reason it could be useful to discuss the simulation results in terms of final energy utilization.

\section{REFERENCES}

[1] G.N. Spyroupoulos, C.A. Balaras, "Energy consumption and potential of energy savings in Hellenic office buildings used as bank branches: a case study", Energy and Buildings 43, 770-778, 2011.

[2] P. Penna, A. Prada, F. Cappelletti, A. Gasparella, "Multi-objectives optimization of Energy Efficiency Measures in existing buildings", Energy and Buildings 95, 57-69, 2015.

[3] D. Griego, M. Krarti, A. Hernandez-Guerrero, "Energy efficiency optimization of new and existing office buildings in Guanajuato, Mexico", Sustainable Cities and Society 17, 132-140, 2015.

[4] M. Aksoezen, M. Daniel, U. Hassler, N. Khoeler, "Building age as an indicator for energy consumption", Energy and Buildings 87, 74-86, 2015.

[5] D. B. Crawley, L. K. Lawrie, C. Winkelmann, W.F. Buhlc, Y. J. Huang, C. O. Pedersen, R. K. Strand, R. J. Liesend, D. E. Fisher, M. J. Witte, J. Glazer, "EnergyPlus: creating a new-generation building energy simulation program", Energy and Buildings 33, 319-331, 2001. DOI: 10.1016/S0378-7788(00)00114-6 
[6] R. De Lieto Vollaro, C. Guattari, L. Evangelisti, G. Battista, E. Carnielo, P. Gori, "Building energy performance analysis: A case study", Energy and Buildings 87, 87-94, 2015.

[7] A. Boyano, P. Hernandez, O. Wolf, "Energy demands and potential savings in European office buildings: Case studies based on EnergyPlus simulations", Energy and Buildings 65, 19-28, 2013.

[8] "Decreto Interministeriale 26 Giugno 2015", Italian Ministry for the Economic Development (MISE), Official Bulletin, 2015.

[9] Z. Wu, X. Xia, B. Wang, "Improving building energy efficiency by multi-objective neighbourhood field optimization", Energy and Buildings 87, 45-56, 2015.

[10] http://www.a2pbeer.eu [Accessed 14 Jan. 2016]

[11] E. U. Finlayson, D. K. Aristech, C. Huizenga, M. D. Rubin, M. S Reilly, "Window 4.0: Documentation of Calculation Procedures.", Report Number: LBL-33943, 1993.

[12] "UNI EN ISO 14683:2008", Italian Standard Bureau UNI, 2008.

[13] "UNI EN ISO 10211:2005", Italian Standard Bureau UNI, 2005.

[14] K. Martin, A. Erkoreka, I. Flores, M. Odriozola, J.M. Sala, "Problems in the calculation of thermal bridges in dynamic conditions", Energy and Buildings 43, 529-535, 2011.

[15] K. Martin, C. Escudero, A. Erkoreka, I. Flores, J.M. Sala, "Equivalent wall method for dynamic characterization of thermal bridges", Energy and Buildings 55, 704-714, 2012.

[16] A.E. Ben-Nakhi, "Development of a integrated dynamic thermal bridging assessment environment", Energy and Buildings 35, 375-382, 2012.

[17] S.A. Al-Sanea, M.F. Zedan, "Effect of thermal bridges on transmission loads and thermal resistance of building walls under dynamic conditions", Applied Energy 98, 584-593, 2012.

[18]"UNI EN ISO 13786:1999", Italian Standard Bureau UNI, 1999.

[19] TRNSYS, TESS (Thermal Energy System Specialist), University of Wisconsin, 2000.

[20] "UNI EN ISO 6946:2008", Italian Standard Bureau UNI, 2008.

[21] "ISO 13790:2008", International Organization for Standardization, 2008.

[22] "UNI EN 15193:2008", Italian Standard Bureau UNI, 2008.

[23] "Commission Delegated Regulation (EU) No 1194/2012", European Parliament, Official Journal of the European Union, 2012.

[24] "Ligurian Regional Regulation n. 6 of November 13th", Official Liguria Region Bulletin, 2012.

[25] Eneritz B., et al. (2013), "Annex 1: Description of work, part B", Integration of technologies for energy-efficient solutions in the renovation of public buildings, Europe, p. 11.

[26] "Buildings Energy Data Book (2010)", U.S. Department of Energy - Office of Energy Efficiency and Renewable Energy, USA.

\section{NOMENCLATURE}

U thermal transmittance, W. $\mathrm{m}^{-2} \cdot \mathrm{K}^{-1}$

$\mathrm{d} \quad$ wall layer material width, $\mathrm{m}$

Awall wall area, $\mathrm{m}^{2}$

$\dot{\mathrm{Q}}$ heat transfer rate, $\mathrm{W}$ 


$\begin{array}{ll}\dot{\mathrm{Q}}^{\prime} & \text { heat transfer rate per unit length, W. } \mathrm{m}^{-1} \\ \mathrm{R} & \text { thermal resistance, } \mathrm{m}^{2} . \mathrm{K} \cdot \mathrm{W}^{-1} \\ \mathrm{~h}_{\mathrm{a}} & \text { convective/conductive air coefficient, W. } \mathrm{m}^{-2} \cdot \mathrm{K}^{-1} \\ \mathrm{~h}_{\mathrm{r}} & \text { radiative air coefficient, W. } \mathrm{m}^{-2} \cdot \mathrm{K}^{-1} \\ \mathrm{~T} & \text { temperature, } \mathrm{K} \text { or }{ }^{\circ} \mathrm{C} \\ \mathrm{H}^{\prime} & \text { mean global heat transfer coefficient, W. } \mathrm{m}^{-2} \cdot \mathrm{K}^{-1} \\ \mathrm{C} & \text { thermal capacity, } \mathrm{J} . \mathrm{K}^{-1} \\ \dot{\mathrm{m}} & \text { mass flow rate, } \mathrm{kg} . \mathrm{s}^{-1}\end{array}$

\section{Greek symbols}

$\lambda$

$\varphi$

$\rho$

$\tau$

\section{Subscripts}

i

tot

S

ext

int

air

Z

$1 \mathrm{D}$ thermal conductivity of the material, W. $\mathrm{m}^{-1} \cdot \mathrm{K}^{-1}$

linear thermal transmittance of the thermal bridge, $\mathrm{W} \cdot \mathrm{m}^{-1} \cdot \mathrm{K}^{-1}$ density, $\mathrm{kg} . \mathrm{m}^{-3}$

time, s

i-th element

total

surface

external

internal

air

zone

one-dimensional 